\title{
REVIEW \\ Perceived effectiveness and mechanisms of community peer-based programmes for Spinal Cord Injuries- a systematic review of qualitative findings
}

\author{
A Divanoglou ${ }^{1,2,3}$ and M Georgiou ${ }^{3,4}$
}

Study design: Systematic review and meta-synthesis of qualitative findings.

Objectives: To establish the perceived effectiveness and mechanisms of community peer-based programmes based on narratives of consumers with spinal cord injury (SCl).

Methods: Scopus, Academic Search Complete, CINAHL, Health Source, Medline, PsycARTICLES, PsychINFO, SPORTSDiscus and ProQuest were searched for articles published in English between January 1990 and December 2015. Qualitative studies referring to community peer-based interventions were included if most cases had a SCl. The results section of included studies was extracted and entered in NVivo. Data were inductively coded and analysed according to the three phases of Thematic Synthesis.

Results: The search yielded 1402 unique records, out of which 126 were scrutinised in full. Four studies were appraised based on eight criteria and were finally included in the analysis. Three analytical themes emerged: (1) a unique learning environment created by the right mixture of learning resources, learning processes and a can-do attitude; (2) peer mentors-a unique learning resource with high level of relatedness that eases and empowers participants; and (3) an intervention that responds to important unmet needs and unrealised potential.

Conclusions: Community peer-based programmes for people with $\mathrm{SCl}$ provide individualised training in important life areas, using a variety of learning resources and a plethora of learning processes. The high level of perceived effectiveness suggests that this type of intervention is an important tool of health systems post discharge from initial rehabilitation. Community organisations should be supported with evaluating their programmes through quality research.

Spinal Cord (2017) 55, 225-234; doi:10.1038/sc.2016.147; published online 15 November 2016

\section{INTRODUCTION}

Spinal cord injury (SCI) has devastating consequences for the individual, their family and their community. ${ }^{1}$ There is convincing evidence that comprehensive SCI systems of care result in fewer complications, better functional outcomes and lower mortality compared with general or non-systematic approaches. ${ }^{2-6}$ Nevertheless, the vast majority of SCI individuals around the world are still managed through non-systematic and fragmented processes. ${ }^{1}$ Only a few countries, all high income, provide comprehensive systems of coordinated care from the acute phase to life-long follow-up. ${ }^{1}$ An increasing number of countries have established stand-alone Spinal Injury Units that focus on early survival and prevention of complications. Despite improvements in rehabilitation efficiency over the last 20 years, shorter rehabilitation length of stay results in lower functional outcomes on discharge. ${ }^{7}$ Post-discharge follow-up, when available, may involve nursing and medical services $^{8}$ or consumer-driven programmes ran by non-profit organisation. ${ }^{1,9}$

Transition from in-patient care to home is a complex process that has been described as one of the most difficult aspects of life after
SCI. ${ }^{9-11}$ Initial inpatient rehabilitation covers a specific set of needs relevant to the acute and early sub-acute phase, but reportedly fails to foresee needs that only become apparent when the person returns home. ${ }^{10,12}$ There is compelling evidence that newly injured individuals feel unprepared physically and psychologically to transition from in-patient care to home. ${ }^{11,12}$ After returning home, individuals with SCI often experience isolation, depression and low levels of physical and psychosocial functioning., ${ }^{90,13-15}$ Low level of self-efficacy was found to have a detrimental effect on adjustment 6 months post discharge. ${ }^{16}$ At the same time, social support and particularly peer support, have been reported as crucial in adjusting to post-discharge life..$^{10,11,15,17-19}$

Peer-based programmes have an important role in the process of re-adjusting in the community. ${ }^{1}$ For the needs of this paper, community peer-based programmes were defined as programmes located in the community that were not part of the initial in-patient or outpatient care and rehabilitation. These programmes may involve health professionals, but training is primarily led by individuals with a lived experience of disability, otherwise known as peer mentors. ${ }^{20}$ World Health Organization recommended the utilisation of

${ }^{1}$ Central Queensland University, School of Human Health and Social Sciences, Physiotherapy Program, North Rockhampton, Australia; ${ }^{2}$ Umeå University, Community Medicine and Rehabilitation Department, Umeå, Sweden; ${ }^{3}$ Alli Opsi, Not-for-profit Organization, Thessaloniki, Greece and ${ }^{4}$ Paphos General Hospital, Paphos, Cyprus

Correspondence: Dr A Divanoglou, Central Queensland University, School of Human Health and Social Sciences, Physiotherapy Program, B34/1.19, Bruce Highway, North Rockhampton, QLD 4702, Australia.

E-mail: anestis.divanoglou@gmail.com

Received 13 April 2016; revised 2 August 2016; accepted 27 August 2016; published online 15 November 2016 
non-health professionals such as peers to assist in the delivery of a comprehensive range of health care and rehabilitation services. ${ }^{1}$ To date, there is little scientific evidence exploring the effectiveness and the effect mechanisms of such interventions in SCI management. Furthermore, there is a lack of systematic reviews exploring this topic.

We therefore conducted a qualitative systematic review with the aim to assess consumer perceptions on the effectiveness of community peer-based programmes in SCI management. Furthermore, this systematic review aimed to identify and synthesise the mechanisms that contribute to the reported outcomes. Qualitative systematic reviews are considered a powerful tool for informing evidence-based policy and practice. Meta-synthesis is the type of qualitative systematic review that uses rigorous qualitative methods to synthesise and integrate findings from existing qualitative studies in order to construct greater meanings through an interpretative process. ${ }^{21}$ It is widely accepted that systematic reviews should consider diverse forms of evidence, both quantitative and qualitative. ${ }^{22}$ Only then can a complete story be explored and understood.

\section{MATERIALS AND METHODS}

We followed the guidelines for Enhancing Transparency in Reporting the synthesis of Qualitative Research to report the methodology. ${ }^{23}$ Based on the critical realism paradigm, we used the method of Thematic Synthesis as described by Thomas and Harden. ${ }^{24}$ Thematic synthesis was developed to conduct reviews that addressed questions relating to intervention need, appropriateness and acceptability—as well as those relating to effectiveness-without compromising on key

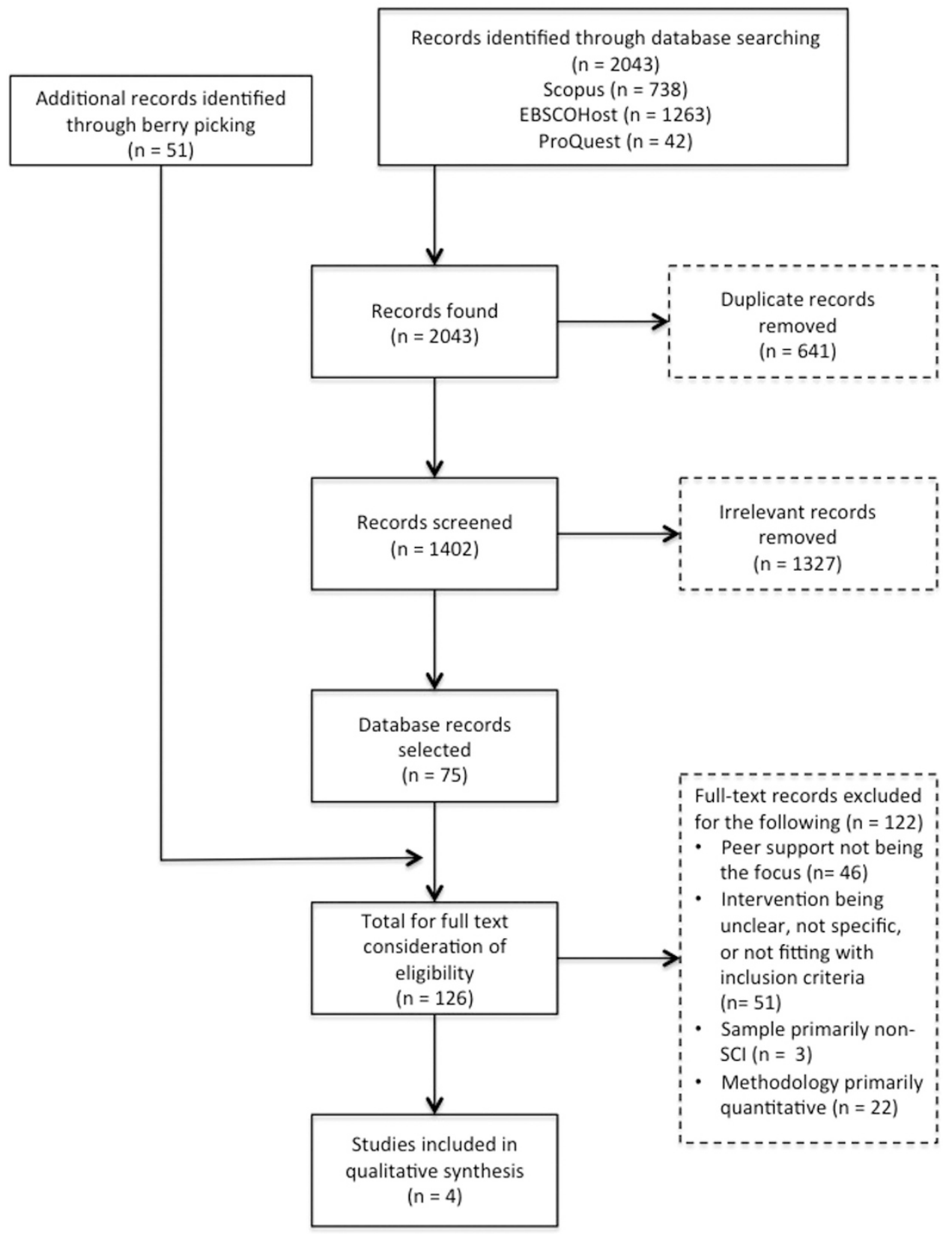

Figure 1 Flow chart of search and selection processes. 
principles developed in systematic reviews. ${ }^{25}$ The outcome of thematic synthesis is a list of analytical themes that go beyond the findings of the primary studies.

During the review process, the two reviewers held regular debriefing sessions in which the methodological choices and data analysis procedures and interpretations were discussed and negotiated. Any discrepancies were resolved by consensus-a process that has been described as 'negotiated validity' in qualitative methodology. ${ }^{26}$ In our fortnightly sessions, we used a 'think aloud' strategy ${ }^{26}$ to articulate personal perspectives and to discuss reasons for agreement or disagreement on each topic. If consensus was not reached at one meeting, the topic was moved to the following meeting until consensus was reached. We used an 'audit trail' format to document all major methodological decisions, as a way to better understand decision processes and to enhance reflexivity of teamwork. ${ }^{27}$

\section{Inclusion and exclusion criteria}

According to Sandelovski and Barroso, inclusion and exclusion criteria in meta-synthesis are reconsidered throughout the stages of the review process and are influenced by the identified studies. ${ }^{26}$ Defining the criteria for our study was a dynamic process that continued into the stage of literature search. Our final list of inclusion and exclusion criteria was as follows:

1. Qualitative studies were included independently of their design and epistemological framework; mixed-method studies were only included if the qualitative part was substantial, that is, at least equal in length and weight to the quantitative part. Studies without original quotes to support the researchers' interpretations were excluded.

2. Studies published in English between January 1990 and December 2015.

3. Original articles and grey literature such as digital theses and research reports.

4. Studies with adequately described interventions that had the following characteristics:

a. Interventions offering a face-to-face, direct, real-time and mutually interactive experience.

b. Community interventions that were not part of the initial inpatient or outpatient care and rehabilitation.

c. Formal peer support interventions (that is, not incidental) that used designated peer workers in a paid or volunteer role.

Table 1 Study characteristics

\begin{tabular}{|c|c|c|c|c|c|c|}
\hline $\begin{array}{l}\text { First author, } \\
\text { year, country }\end{array}$ & $\begin{array}{l}\text { Participants } \\
\text { (N, ages, M/F) }\end{array}$ & Other participants & $\begin{array}{l}\text { Methodological } \\
\text { approach }\end{array}$ & Data collection & $\begin{array}{l}\text { Time of data } \\
\text { collection }\end{array}$ & Aim \\
\hline Block, USA 33 & $\begin{array}{l}19(10 \text { with } \\
\mathrm{SCl})^{\mathrm{a}} \\
\text { M/F: } 3 / 2^{\mathrm{b}} \\
\text { Mean age: } 44 \\
\text { years (range: } \\
\text { 20-73) }\end{array}$ & $\begin{array}{l}\text { Multiple sclerosis and other } \\
\text { neurological conditions }\end{array}$ & $\begin{array}{l}\text { Content and the- } \\
\text { matic discourse } \\
\text { analysis } \\
\text { Convenience } \\
\text { sample }\end{array}$ & $\begin{array}{l}\text { Semi-structured } \\
\text { interviews, } \\
\text { Personal activity } \\
\text { logs (PAL), and } \\
\text { independent } \\
\text { living } \\
\text { Assessments } \\
\text { (ILAS) }\end{array}$ & $\begin{array}{l}6 \text { months post } \\
\text { intervention }\end{array}$ & $\begin{array}{l}\text { Assess the influence of an interven- } \\
\text { tion for capacity building and health } \\
\text { promotion on self-efficacy and the } \\
\text { ability to set and achieve goals, to } \\
\text { recognise supports and to navigate } \\
\text { barriers to goal attainment }\end{array}$ \\
\hline $\begin{array}{l}\text { Standal, } \\
\text { Norway }^{35}\end{array}$ & $\begin{array}{c}20 \text { (11 } \\
\text { with } \mathrm{SCl}) \\
\text { M/F: 4/1 } \\
\text { Mean age: } 43 \\
\text { (age range: } \\
\text { 26-60 years) } \\
\text { Time since } \\
\text { injury: } 1-30 \\
\text { years }\end{array}$ & $\begin{array}{l}\text { Other acquired neurological } \\
\text { conditions }\end{array}$ & $\begin{array}{l}\text { Situated learning } \\
\text { framework } \\
\text { Phenomenological } \\
\text { approach } \\
\text { Hermeneutical } \\
\text { approach }\end{array}$ & $\begin{array}{l}\text { In-depth inter- } \\
\text { views and close } \\
\text { observations } \\
\text { including infor- } \\
\text { mal interviews }\end{array}$ & $\begin{array}{l}\text { Towards the end of } \\
\text { the programme }\end{array}$ & $\begin{array}{l}\text { Investigate the learning that takes } \\
\text { place when people with disabilities } \\
\text { interact in a rehabilitation setting }\end{array}$ \\
\hline $\begin{array}{l}\text { Conway, 2010, } \\
\text { New Zealand }\end{array}$ & $\begin{array}{l}\text { Eight with } \\
\text { SCl } \\
\text { M/F: 7/1 } \\
\text { Time since } \\
\text { injury: 1-14 } \\
\text { years } \\
\text { Age range: } \\
\text { 20-63 }\end{array}$ & $\mathrm{Nil}$ & $\begin{array}{l}\text { Constructivist } \\
\text { Grounded theory } \\
\text { Constant compara- } \\
\text { tive method } \\
\text { Purposeful } \\
\text { sampling }\end{array}$ & $\begin{array}{l}\text { In-depth } \\
\text { semi-structured } \\
\text { individual } \\
\text { interviews. Field } \\
\text { observation } \\
\text { notes }\end{array}$ & $\begin{array}{l}\text { At the beginning of } \\
\text { the programme and } \\
3 \text { months after } \\
\text { completion of the } \\
\text { programme }\end{array}$ & $\begin{array}{l}\text { Gain an understanding of the } \\
\text { experiences and perceptions of } \\
\text { individuals with spinal cord injury } \\
\text { who participate in an outdoor } \\
\text { recreational programme in New } \\
\text { Zealand and he influence it has on } \\
\text { their lives }\end{array}$ \\
\hline $\begin{array}{l}\text { Ashton-Shaeffer } \\
2001, \text { USA }^{32}\end{array}$ & $\begin{array}{c}15 \text { (8 with } \\
\mathrm{SCl} \text { ) } \\
\mathrm{M} / \mathrm{F}: 3 / 2 \\
\text { Age range: } \\
20-50 \\
\text { Mean time } \\
\text { since injury: } \\
10 \text { years } \\
\text { (range: } \\
8 \text { months-18 } \\
\text { years) }\end{array}$ & $\begin{array}{l}\text { Limb malformation, above } \\
\text { knee amputation, below } \\
\text { knee amputation, cerebral } \\
\text { vascular accident, reflex } \\
\text { sympathetic dystrophy }\end{array}$ & $\begin{array}{l}\text { Constant compari- } \\
\text { son techniques } \\
\text { with a grounded } \\
\text { theory approach } \\
\text { Foucauldian fra- } \\
\text { mework, informed } \\
\text { by the work of } \\
\text { poststructural } \\
\text { feminists }\end{array}$ & $\begin{array}{l}\text { Individual, in- } \\
\text { depth, semi- } \\
\text { structured } \\
\text { interviews }\end{array}$ & $\begin{array}{l}6 \text { months } \\
\text { post-intervention }\end{array}$ & $\begin{array}{l}\text { Investigate the attitudes of men and } \\
\text { women with physical disabilities } \\
\text { towards participation in a disability } \\
\text { sport camp }\end{array}$ \\
\hline
\end{tabular}

aNumbers correspond to study participants who were randomly selected for the qualitative part of the study.

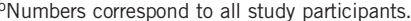


Studies that referred solely to patient-to-patient support were excluded.

5. Studies where at least half of the participants had an SCI.

\section{Search and selection strategies}

Overall, we conducted a comprehensive and rigorous search of the literature with an emphasis on recall rather than on precision, in order to make sure that our search was exhaustive. Electronic database searches were conducted in Scopus, EBSCOHost (Academic Search Complete, CINAHL, Health Source, Medline, PsycARTICLES, PsychINFO, SPORTSDiscus) and ProQuest. The search strategy looked in titles, abstracts and keywords for the terms listed in Supplementary Appendix S1. In addition, the two authors independently followed 'berry-picking' methods, ${ }^{28}$ in order to further expand the search strategy. These involved footnote chasing, citation searching, journal run, author searching, as well as a search in websites of organisations known to run community peer-based interventions. In order to keep data analysis manageable, we only considered dissertations if there was no published article linked to the study.

\section{Data evaluation}

All identified studies that met the inclusion criteria were appraised for their trustworthiness and usefulness based on the set of eight criteria suggested by Rees et al. ${ }^{29}$ First, the two reviewers independently appraised, weighted and justified the weighting of each of the studies. Then, any discrepancies were discussed and resolved through consensus. No articles were excluded on the basis of insufficient quality. Rather, the appraisal process was used to get a better understanding of the strengths and weaknesses of each article.

\section{Data analysis}

All included studies were entered verbatim in NVivo 10. In accordance with the recommendations by Thomas and Hardsen, ${ }^{24}$ the unit of analysis for our review was the 'results' or 'findings' section of the primary sources. Thematic synthesis involved the following three stages: the coding of text 'line-by-line'; the development of 'descriptive themes'; and the generation of 'analytical themes'. ${ }^{24}$

In the first stage of analysis, we started with an inductive, opencoding process. Initially, one primary source was coded and the identified codes were then discussed between the reviewers. Subsequent primary sources were coded into pre-existing nodes, and new nodes were created when deemed necessary. Coding was an inclusive, recursive process, in which we continuously revisited previous decisions to determine whether coding was being implemented systematically and consistently.

When initial coding of all primary sources was completed, the reviewers reconsidered all identified codes with the aim to condense them and subsequently group them into unique categories and subcategories. In order to explore the effect mechanisms of the identified programmes, we used Donabedian's framework for assessment of health-care quality (that is, structure-process-outcomes), as a starting point to group the descriptive categories. ${ }^{30}$ This process of reciprocal translation, synthesis of translation and grouping of categories led to the identification of overarching descriptive themes that emerged from primary data sources. ${ }^{24,31}$

In the final stage of thematic synthesis, analytical themes emerged when we related the descriptive themes to our research questions.

\section{RESULTS}

\section{Included studies}

Figure 1 presents a flow chart with the search and selection process. All 2043 records from database searching were entered into EndNote X7 software. After removal of duplicates, results were first screened based on title and abstract. The full article of the resulting 75 records was retrieved, and their reference lists were scrutinised to identify other relevant studies. A total of 51 records were identified through reference scrutinising and berry-picking methods. These 126 articles were then read in full by the two authors independently, and were either classified as included or excluded. The primary reason for not including an article was clearly identified and assigned into one of the four categories presented in Figure 1.

Four studies met the selection criteria and were included in this review: Ashton-Shaeffer et al.; ${ }^{32}$ Block et al.; ${ }^{33}$ Conway; ${ }^{34}$ and Standal and Jespersen. ${ }^{35}$

\section{Characteristics of the included studies}

Characteristics of the four included studies are presented in Table 1. Each of the four studies referred to an established peer-based programme: Wheels in Motion in Norway; ${ }^{35}$ Shake it Up in USA $;^{33}$ Sports Camp in USA ${ }^{32}$ and Back Up in New Zealand. ${ }^{34}$ One of the studies included only SCI participants $(N=8)$, whereas the other three included an equal number of cases with SCI $(N=35 / 70)$ and cases with other neurological conditions. One study collected data towards the end of the programme, another one 3 months after completion and the other two 6 months after completion of the programme.

The key characteristics of the included programmes are presented in Supplementary Appendix S2. The two programmes from USA were collaborations between non-profit community organisations and universities. Only Wheels in Motion and Back up were residential programmes. All programmes provided a combination of outdoor activities and adapted sports, training sessions focusing on physical skills, theoretical sessions and discussions. All programmes used peer mentors, rehabilitation professionals and non-disabled assistants.

Two of the studies were assessed as high quality, one as medium to high, and one as low quality. Table 2 presents the results of the quality appraisal process.

\section{Descriptive themes}

Analysis of the four primary sources led to the identification of the descriptive themes, categories and codes. Table 3 presents a visual representation of descriptive themes, categories and sub-categories organised in a way that could explain the effect mechanisms of the programmes. A comprehensive list of the descriptive themes is provided in Table 4.

Table 2 Appraisal of included data sources for (a) reliability of findings and (b) usefulness of findings

Trustworthiness of findings Usefulness of findings

\begin{tabular}{|c|c|c|c|c|c|c|c|}
\hline & & Low & Medium & High & Low & Medium & High \\
\hline 1. & Block et al. ${ }^{33}$ & $\sqrt{ }$ & & & $\sqrt{ }$ & & \\
\hline 2. & Standal and Jespersen ${ }^{35}$ & & & $\sqrt{ }$ & & & $\sqrt{ }$ \\
\hline 3. & Conway ${ }^{34}$ & & & $\sqrt{ }$ & & & $\sqrt{ }$ \\
\hline 4. & Ashton-Shaeffer et al. ${ }^{32}$ & & $\sqrt{ }$ & & & & $\sqrt{ }$ \\
\hline Total & & 1 & 1 & 2 & 1 & & 3 \\
\hline
\end{tabular}


Table 3 Descriptive themes, categories and sub-categories

\begin{tabular}{|c|c|c|c|c|c|c|}
\hline \multicolumn{4}{|c|}{ Mechanisms } & \multicolumn{3}{|c|}{ Effects } \\
\hline Learning & \multicolumn{3}{|c|}{ Learning Processes \& Activities } & Outcomes - & Outcomes - & Significance - \\
\hline \multirow{2}{*}{$\begin{array}{cl}\text { Curriculum } \\
\circ & \text { Structure } \\
\circ & \text { Flexibility } \\
\circ & \text { Content }\end{array}$} & & \multirow{10}{*}{ 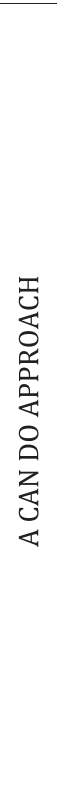 } & Observing & $\begin{array}{l}\text { Dare to try/push } \\
\text { boundaries }\end{array}$ & Started work & \\
\hline & $\begin{array}{l}\text { Participating in a } \\
\text { group }\end{array}$ & & Discussing & Motivate - inspire & $\begin{array}{l}\text { Connected and did } \\
\text { stuff with others }\end{array}$ & First time \\
\hline \multirow{3}{*}{$\begin{aligned} \text { Participants } \\
\circ \text { Needs } \\
\circ \text { Expectations } \\
\circ \text { Goals } \\
\circ \text { Function }\end{aligned}$} & & & Doing & $\begin{array}{l}\text { Set standard - } \\
\text { measuring stick }\end{array}$ & Got a partner & \\
\hline & $\begin{array}{l}\text { Getting together } \\
\text { has a power }\end{array}$ & & Comparing & Can do culture & & $\begin{array}{l}\text { Did not know it } \\
\text { was possible }\end{array}$ \\
\hline & & & Reflecting & $\begin{array}{l}\text { Improve self- } \\
\text { efficacy }\end{array}$ & $\begin{array}{l}\text { Became more } \\
\text { socially active }\end{array}$ & \\
\hline One's own self & $\begin{array}{l}\text { Training in a safe } \\
\text { environment }\end{array}$ & & Competing & $\begin{array}{l}\text { Improve self- } \\
\text { confidence }\end{array}$ & $\begin{array}{l}\text { Improved } \\
\text { community access }\end{array}$ & Transition point \\
\hline \multirow[t]{3}{*}{$\begin{aligned} & \text { Peer mentors } \\
& \text { - } \text { A living } \\
& \text { example } \\
& \text { - } \text { Credibility } \\
& \text { - } \text { Relatedness } \\
&\end{aligned}$} & & & $\begin{array}{l}\text { Dealing with } \\
\text { fears }\end{array}$ & Forming identity & $\begin{array}{l}\text { Managed day on } \\
\text { their own }\end{array}$ & $\begin{array}{l}\text { Transformational } \\
\text { experience }\end{array}$ \\
\hline & & & $\begin{array}{l}\text { Using own } \\
\text { jargon/language }\end{array}$ & $\begin{array}{l}\text { Feeling normal and } \\
\text { accepted }\end{array}$ & $\begin{array}{l}\text { Improved } \\
\text { wheelchair skills }\end{array}$ & $\begin{array}{l}\text { Exceeded initial } \\
\text { expectations }\end{array}$ \\
\hline & $\begin{array}{l}\text { Engaging in } \\
\text { stimulating } \\
\text { activities }\end{array}$ & & $\begin{array}{l}\text { Individualize } \\
\text { knowledge }\end{array}$ & $\begin{array}{l}\text { Set new goals and } \\
\text { worked towards } \\
\text { realizing them }\end{array}$ & $\begin{array}{l}\text { Learnt and } \\
\text { practiced } \\
\text { recreational and } \\
\text { sports activities in } \\
\text { the community }\end{array}$ & $\begin{array}{l}\text { A unique } \\
\text { opportunity not } \\
\text { available } \\
\text { elsewhere }\end{array}$ \\
\hline Health Professionals & & & Supporting & & & \\
\hline
\end{tabular}

\section{Analytical themes}

When we related the descriptive themes to the research questions, three analytical themes emerged. The three analytical themes were: (1) a unique learning environment created by the right mixture of learning resources, learning processes and a can-do attitude; (2) peer mentors-a unique learning resource with high level of relatedness that eases and empowers participants; and (3) an intervention that responds to important unmet needs and unrealised potential. Table 4 presents the mapping of both analytical and descriptive findings with the primary sources. Supplementary Appendix S3 presents illustrative quotes for the descriptive themes under each analytical theme.

\section{A unique learning environment created by the right mixture of} learning resources, learning processes and a can-do attitude

In community peer-based programmes, learning derived from multiple sources, it took place throughout the day and it involved a plethora of processes. Although each programme had its own characteristics, a common key theme across all the programmes was the prevailing cando attitude. ${ }^{32-35}$ Learning resources and learning processes were not linked with outcomes in a one-to-one cause-effect manner. Rather, specific outcomes were a result of a combination of resources and processes. The most important learning resources were seen as the curriculum structure, the content of the programme, the peer mentors and one's self.

Most of the curricula were described as having a flexible structure that allowed participants to engage in the scheduled activities and informal learning opportunities. ${ }^{32,34,35}$ As a result, participants gained the opportunity to individualise the learning experience to their own level and needs, as well as to informally interact with peers. Overall, most of the programmes were described as challenging, but at the same time flexible and possible to follow. ${ }^{32,34,35}$

The type of training and activities offered in each programme was yet another important resource that made it a unique learning environment. All programmes included training of physical skills, recreational activities and sports, as well as information sessions on topics such as assistive equipment, modifications and other issues relevant to living with $\mathrm{SCI} .{ }^{32-35}$

Connecting with a peer mentor was a personal process for each participant. In most programmes, being a model for other participants was a role filled by peer workers as well as by experienced participants. $^{32,34,35}$ Peer workers were designated by the programme organisers prior to the programme, whereas the experienced peers were informally nominated by participants and emerged during the programme.

Learning also occurred between inexperienced participants who learnt from each other. Being part of a group of individuals with similar functional level and goals allowed participants to share knowledge, skills and experiences. ${ }^{32-35}$ At last, learning did not always come from an external source. Participants commented that one's self was also an important source of learning. ${ }^{34}$

Observing peer mentors and other participants demonstrate skills was reported to be an important learning process. ${ }^{32-35}$ On some occasions, participants then performed multiple attempts to master the skill. On other occasions, observing others was associated with comparing one's own level of injury and independence with other participants. Often, comparison led to competition, which was seen as motivating and empowering.

Discussing and negotiating were two other processes that were identified. These processes were often used to transfer knowledge, to 
Table 4 Analytical and descriptive findings: the contribution of each study

\begin{tabular}{|c|c|c|c|c|}
\hline Programmes & $\begin{array}{c}\text { Project } \\
\text { shake it up }\end{array}$ & $\begin{array}{l}\text { Wheels in } \\
\text { motion }\end{array}$ & $\begin{array}{c}\text { Back up } \\
\text { New Zealand }\end{array}$ & $\begin{array}{l}\text { Sports } \\
\text { camp }\end{array}$ \\
\hline Author/s, year \& country & Block et al. ${ }^{33}$ & $\begin{array}{l}\text { Standal and } \\
\text { Jespersen } \\
35\end{array}$ & Conway ${ }^{34}$ & $\begin{array}{c}\text { Ashton-Shaeffer } \\
\text { et al. }\end{array}$ \\
\hline
\end{tabular}

\section{Analytical themes}

Descriptive themes

1. A unique learning environment created by the right mixture of learning resources,

learning processes and a can-do attitude

1.1. Curriculum: right balance of flexibility and structure. A combination of formal sessions and informal learning opportunities

1.2. Content: what is possible to achieve; combine autonomy in choice, exploration, competence and enjoyment

1.3. Peer mentors: peer workers and experienced peers as role models for the participants

1.4. Participants: being part of a group with similar functional level and/or goals is a valuable learning resource

1.5. Learning from one's own self

1.6. Learning processes that facilitate self-reflection, incorporation of the knowledge into practice and build competence

1.7. Not fixing problems, but rather providing the tools 1.8. Learning processes that facilitate the relatedness with peers

1.9. A 'can-do' mindset that empowers and facilitates the learning processes

2. Peer mentors-a unique learning resource with a level of relatedness that empowers participants

3. An intervention that responds to unmet needs and unrealised potential that are important

Total contribution of each study

Analytical themes

Descriptive themes

2.1. Peer mentors actively involved in both formal and informal learning processes of the programme

2.2. Peer mentors have lived it all

2.3. Peer mentors versus able-bodied professionals

2.4. Credible for what they can and what they cannot do 2.5. Why do they bother?

3.1. Unmet needs related to knowledge of potentialchoices, competence in abilities and relatedness with people who speak the same language

3.2. Unrealised potentials prior to the programme.

Possibilities become apparent through interaction with others

3.3. Cognitive, affective and behavioural changes at the programmes led to realisation of needs and possibilities, and to self-determined actions (outcomes)-leading to significant outcomes that can be retained

3.4. An intervention that addresses crucial life areas for the participants

3.5. Short intervention leading to important outcomes

$\sqrt{ }$

$\sqrt{ }$

$\sqrt{ }$

$\sqrt{ }$

$\begin{array}{cccc} & \sqrt{ } & \sqrt{ } & \sqrt{ } \\ \sqrt{ } & \sqrt{ } & \sqrt{ } & \sqrt{ } \\ & \sqrt{ } & \sqrt{ } & \sqrt{ } \\ \sqrt{ } & \sqrt{ } & \sqrt{ } & \sqrt{ } \\ & & & \\ \sqrt{ } & \sqrt{ } & \sqrt{ } & \sqrt{ }\end{array}$

$\begin{array}{lll}\sqrt{ } & \sqrt{ } \\ \sqrt{ } & \sqrt{ }\end{array}$

$\sqrt{ }$

$\checkmark$

$\sqrt{ }$

$\sqrt{ }$

$\sqrt{ } \quad \sqrt{ }$

$\sqrt{ }$

$\sqrt{ }$

$\sqrt{ }$
$\sqrt{ }$
$\sqrt{ }$
$\sqrt{ }$
$\sqrt{ }$
$\sqrt{ }$

$\sqrt{ }$

$\checkmark$

$\sqrt{ }$

$\checkmark$

$\sqrt{ }$

$\sqrt{ }$

\begin{tabular}{cccc} 
& $\sqrt{ }$ & $\sqrt{ }$ & $\sqrt{ }$ \\
& $\sqrt{ }$ & $\sqrt{ }$ & $\sqrt{ }$ \\
& $\sqrt{ }$ & $\sqrt{ }$ & $\sqrt{ }$ \\
& & & \\
$\sqrt{ }$ & $\sqrt{ }$ & $\sqrt{ }$ & $\sqrt{ }$ \\
$\sqrt{ }$ & $\sqrt{ }$ & $\sqrt{ }$ & $\sqrt{ }$ \\
& & & \\
$7 / 3$ & $3 / 3$ & $3 / 3$ & $3 / 3$ \\
$7 / 19$ & $17 / 19$ & $18 / 19$ & $12 / 19$ \\
\hline
\end{tabular}


develop a positive mindset and to strengthen the sense of belonging to the group. Participants felt that they had the opportunity to use their own language freely, which was different to that used by health professionals. This was seen as a way to reclaim their identity.

Participants acknowledged that getting together with others who were in a similar situation and faced similar issues was empowering. ${ }^{34,35}$ The sense of safety, support and collegiality facilitated the relatedness of the participant with peers. In such a learning environment, seeing others dealing with fears, motivated participants to push their own boundaries. Participants commented that instead of being given the solutions to their problems, they had to learn how to solve problems. ${ }^{34}$

\section{Peer mentors - a unique learning resource with high level of relatedness to participants that eases and empowers}

Although peer mentors were highly involved in training and education, their role extended much further than that. ${ }^{32,34,35}$ They worked with motivating the participants to develop a positive mindset and persistence. ${ }^{32,34,35}$ Peer mentors were described as having credibility because 'they have lived it all' and because they developed high level of relatedness with the participants. ${ }^{34,35}$ These attributes were described as unique to peer mentors, as these could not be offered by non-disabled health professionals. ${ }^{34,35}$

Peer mentors were described as a living example of what the participants could achieve and a resource for how to achieve it. At the same time, sharing openly their own limitations made participants feel comfortable with the idea of not being able to manage everything. Therefore, peer mentors were credible both for what they could and could not achieve. ${ }^{35}$ Peer mentors undertook their role either because they had a sense of duty to help those in need, or because they had similar personal experiences in the past, or lastly, because they benefitted personally through that role. ${ }^{34,35}$

\section{An intervention that responds to important unmet needs and unrealised potential}

Some participants admitted having vital unmet needs prior to the programme. They knew why they attended the programme and what they wanted to get out of it. ${ }^{32,34,35}$ Unmet needs were often related to lack of skill and motivation to perform physical activities. Others reported that they lacked the confidence to be in less-protective environments than their homes or the rehabilitation centre.

Some other participants had not realised their full potential, as they did not know what was possible to achieve, particularly in relation to major life areas, such as living independently without a personal assistant, being able to travel, socialise effectively and get a partner. ${ }^{32,34,35}$ These potentials only became apparent to them during the programme through observing and interacting with peers. ${ }^{32,34,35}$ Many participants reported not knowing that it was possible to perform so many activities and live an active life after injury. Some participants reported that they were missing the relatedness with others in a similar condition, and they saw the programme as a unique opportunity to do so. ${ }^{32,34,35}$

For the participants, gaining a better understanding of what was possible to achieve and being encouraged to explore boundaries contributed to developing a can-do culture. ${ }^{32-35}$ This positive mentality and the availability of the peer mentors' and the other participants' living example motivated individuals to accomplish their own goals. ${ }^{32-35}$ This in turn led to higher perceived self-efficacy and self-confidence. ${ }^{32-35}$

Changes occurring at cognitive, affective and behavioural levels during the programme led to realisation of needs and opportunities, which in turn led to more self-determined actions. ${ }^{29,31-33}$ As a consequence, self-determined actions led to outcomes that were more likely to be retainable in the future. Participants reported improvements in wheelchair skills, community access, being more socially active, being able to enjoy activities that they always liked, achieving higher self-confidence and independence. ${ }^{32-35}$ Overall, they were able to increase their level of physical activity by getting involved in recreational activities and sports that they had tried during the programme.

Overall, participation in the programme was a transformational experience for many participants and a transition point for achieving higher level of functioning, well-being and identity rebuilding. ${ }^{32-35}$ For some of them, the programme was the first time they performed activities as advanced as doing kayaking, or as basic as leaving their house. An illustrative quote from one of the participants stated 'I (had not) left my house in 3 years before I met you guys' (Dora). ${ }^{33}$ However, for Carla, a 41-year-old physical education teacher, it was return to work that she achieved through the skills and the confidence she had gained in the programme. ${ }^{32}$

\section{DISCUSSION}

This is the first attempt to systematically identify and synthesise findings of qualitative studies in order to explore the mechanisms and perceived effectiveness of community peer-based programmes in SCI management. Our findings suggest that community peer-based programmes result in positive outcomes for community-dwelling individuals with SCI. Exploration of the effect mechanisms revealed a plethora of learning resources and processes, and highlighted the role of peer mentoring.

1. A unique learning environment created by the right mixture of learning resources, learning processes and a can-do attitude Learning occurred during formal (that is, scheduled sessions) and informal opportunities (interactions with peers and peer mentors), involved various processes (for example discussing, observing, doing, incorporating, following), and came from various directions (that is, from experienced peers, peer workers, inexperienced peers, health professionals). This is a unique learning environment, different to other settings or programmes, such as inpatient rehabilitation, ${ }^{36}$ therapeutic recreation, ${ }^{37}$ leisure activity programmes, ${ }^{38}$ wheelchair sports, ${ }^{39}$ support groups, ${ }^{20}$ non-face-to-face or one-to-one peer mentoring programmes. ${ }^{40}$

The first and foremost mechanism of the community peer-based programmes could be summarised by what Perlan called in his dissertation 'Gathering has a power'. ${ }^{41}$ In the case of Project Quila in Mexico described in Perlan's study, gatherings of local people with disability at a local hotel resulted in the development of a consumer-led rehabilitation centre. ${ }^{41}$ In the case of community peer-based programmes, gathering of many people with a SCI became a transformational experience for those attending. Community peer-based programmes are an effective form of participatory learning.

Our analysis demonstrated that through the prevalent can-do attitude in the programmes, participants developed a high level of perceived efficacy in performing tasks that were important for them. This is important given that higher level of self-efficacy has been reported to improve resilience and to reduce the risk for depressed mood in people with SCI after discharge. ${ }^{42,43}$ According to Bandura, ${ }^{44}$ self-efficacy beliefs are an important aspect of human motivation and behaviour and influence the actions that can affect one's life. Furthermore, personal accomplishments, vicarious experience, verbal persuasion and physiological feedback build self-efficacy beliefs and set 
the base for expectations and actions in one's life. ${ }^{44}$ The programmes provided many opportunities for participants to experience success and to overcome failures. Mastering a skill has been considered as the most influential source on efficacy. ${ }^{44}$ By observing what their peers achieved, participants were able to improve their self-efficacy beliefs through what Bandura describes as vicarious experience. ${ }^{44}$ Furthermore, verbal persuasion was more effective as it came from the sources that were considered credible, that is, peer mentors, as compared with non-disabled instructors.

In addition, the programmes offered a dynamic learning environment that facilitated the satisfaction of the three basic needs postulated in self-determination theory, that is, the need for autonomy, competence and relatedness. ${ }^{45-47}$ According to self-determination theory, satisfaction of these needs fosters an internalised motivation for changes in behaviour, which makes it more likely for the person to achieve long-term adherence. ${ }^{45-47}$ Participants of the programmes became more internally motivated, because they felt competent in performing a certain behaviour, they were provided with choices on how to accomplish it and they felt connected with significant others.

The learning environment was also described as supportive and flexible, offering a plethora of learning resources and processes. Such an environment helped participants to feel safe, overcome their fears, encouraged them to try activities and led them to push their own boundaries. The relationship between learning resources, processes and outcomes was not linear or pre-determined. Rather, from the available learning resources and processes, the participants picked the ones that best suited their needs. That unique combination differed from participant to participant, that is, learning resources and processes that worked for one participant did not necessarily work for another. Therefore, the available set of learning resources and processes could be seen as a toolbox, where participants pick the tools that work best for them. It was the flexibility of the programme that facilitated participants to pick and choose the right tools for themselves, and thus to customise the intervention to their personal needs. Client-centredness can be seen as an integral part of community peer-based programmes.

\section{Peer mentors - a unique learning resource with high level of relatedness that eases and empowers participants}

The availability of peer mentors (for example, designated peer workers and emergent experienced peers) as a source of learning made the programmes a hive of observational learning. Although the exact roles and responsibilities of peer mentors were somewhat different, modelling of behavioural skills was a common process in the programmes. Peer mentors are considered credible because their lived experience makes them convincing, live representations of what participants could achieve if they wanted and made the effort. According to Bandura, modelling is much more than mimicry, as it involves higher level processes that allow the observer to extract the rules governing specific judgments and actions, in order to generate new courses of behaviour that go beyond what was seen or heard. ${ }^{48}$

In addition to being a credible learning resource, as noted above, peer mentors have high degree of relatedness with participants. Relatedness is considered a result of acceptance, understanding and taking responsibility for the well-being of others. ${ }^{45,46}$ Peer mentors understand the needs of participants and respect their feelings primarily because of their common lived experience of disability. In this way, participants feel valued and accepted. Furthermore, by using a language that is built on their common experiences, participants feel understood and connected with peer mentors. The feeling of relatedness helps participants find relevance in what peer mentors represent, it makes learning worthwhile, and it positively influences learning efficacy.

Furthermore, the peer mentors' role was characterised as motivational. It has been suggested that through cognitive representation of future outcomes, individuals can generate current motivators of behaviour. ${ }^{44,49}$ According to a systematic review by Ginis et al. ${ }^{49}$ peer mentors are an important source of social influence that can impact theoretically relevant motivational determinants of behaviour such as self-efficacy, perceptions of competence and self-determination. The availability of peer mentors with different characteristics and socio-cultural backgrounds suited participants with differing needs and learning styles.

The three key features of peer mentoring, that is, credible learning resource, high degree of relatedness and motivators, make peer mentors a unique learning resource.

\section{An intervention that responds to important unmet needs and unrealised potential}

During the chronic phase of SCI, there are factors that facilitate (that is, self-efficacy, motivation, access to learning resources in an appropriate learning environment, access to peers) and factors that hinder (for example, fear, lack of knowledge, isolation, lack of basic skills, depression) the achievement of outcomes. ${ }^{15,50}$ The current review found that community peer-based programmes endorsed the facilitating factors and minimised the hindering factors through a plethora of learning processes. Participants achieved positive outcomes in significant life areas, such as independent living, employment, leisure and social life.

With SCI being a condition that, in most instances, leads to life-long disability, affected individuals have extensive needs that, if not addressed appropriately, can create an unbearable burden for the health-care system, the family and the individual. Following initial discharge, SCI individuals are reported to have more than double the number of hospital visits and three times longer hospitalisation duration per person per year as compared with the general population. ${ }^{51}$ Despite all four programmes taking place in countries with well-developed and well-functioning systems of care for SCI (USA, Norway, New Zealand), participants reported significant unmet needs prior to the programmes. Many of these needs, that involved major life areas, were satisfied through participation in the community peer-based programmes. In well-functioning systems of care, community peer-based programmes fill an important service gap in long-term SCI management. It may be possible that these programmes fill even bigger service gaps in countries with less well-functioning systems.

\section{Need for more research evidence about community peer-based interventions}

As modern health-care costs are rising, health systems strive for becoming more evidence-based. ${ }^{52}$ Policy makers need solid and convincing proof that an intervention is effective and that it saves money in the short and long term. The current systematic review found that only a very small number of community peer-based programmes for individuals with SCI have been evaluated systematically. More specifically, the systematic literature search yielded a number of small-scale papers that lacked robust methodological design or a clear description of the intervention. We therefore face a paradoxical situation, where there are many community-based interventions, a lot of anecdotal evidence on their effectiveness, very 
little quality research on these programmes, low level of integration in health-care systems and limited funding of these programmes.

Given that community peer-based programmes are usually offered by not-for-profit organisations, there are many possible factors contributing to this paradox. These organisations focus and allocate their limited resources on finding participants and funding. Often, they are dependent on volunteers with expertise but with limited time. In other instances, the programmes may be very labour intensive and with limited number of hands, there is not enough time and energy to conduct research. Also, standardisation or even detailed description of the intervention is often lacking, making it even more difficult to perform any meaningful and generalisable research. Perhaps, exploring the effectiveness and cost-efficiency has not been made an explicit requirement for not-for-profit organisations. Finally, a lack of expertise in designing and conducting quality research might be a major deterring factor.

\section{Research implications}

In agreement with previous studies, this review highlights the importance of collaboration between community organisations and universities as a solution to the paradox and its contributing factors. ${ }^{53}$ Universities often have the interest and the expertise in conducting quality research and in securing research funding. At the same time, community organisations are engaged with the consumers, and they can identify important real-life problems that need solutions. A great example of multidisciplinary community-university partnership was implemented in Canada. ${ }^{53}$ Action Canada is a partnership of university (researchers) and a community-based organisation with the goal to increase physical activity among adults with SCI. That study concluded with a description of challenges, opportunities and lessons learned through this community-university partnership. ${ }^{53}$

\section{Policy implications}

Even in the presence of comprehensive systems of care, community peer-based programmes are needed to cover unmet needs in important life areas. Often, peer support programmes have an ancillary role to medical rehabilitation and treatment. In some instances, these interventions are not part of the formal system of care, which means that they are not subsidised accordingly. Findings of this review suggest that the high levels of perceived effectiveness necessitate the higher integration of community peer-based programmes in health-care systems, and the provision of adequate long-term funding.

Associating funding with evidence-based outcomes relevant to the goals of the organisation and the population they serve could be a way to encourage community organisations to evaluate the effectiveness and cost-efficiency of their programmes. At the same time, making community engagement an explicit expectation for university funding could make collaboration between universities and community organisation become a higher priority for both parties. That could galvanise the interest of the universities to conduct quality and meaningful research, and can make a difference for the community.

\section{Clinical implications}

Flexibility of the programmes was found to be a key characteristic that allowed participants to customise the intervention to their own needs and learning style. Flexibility was also found to facilitate formal and informal learning through a range of processes. Community peer-based programmes should strive to offer rich learning environments with learning resources (that is, content and structure of the programme, peer mentors, participants, non-disabled members) that fit the needs of the participants.

\section{Limitations of the review}

Similar to other systematic reviews on community-based programmes, ${ }^{8}$ there is a strong possibility of publication bias in our study. Community peer-based programmes tend to be under-reported, under-described and under-researched. Furthermore, inclusion of studies published in English may potentially be another factor contributing to publication bias. Last, this systematic review included four studies that satisfied the inclusion criteria, all from high-income countries. Therefore, caution needs to be practiced when relating the conclusions of the current review to programmes in mid- and low-income countries.

\section{CONCLUSIONS}

Community peer-based programmes provide individualised active training in important life areas, using a variety of learning resources. A distinct feature of these programmes is the role and contribution of peer mentors. It appears to be the interplay between the learning resources and the plethora of learning processes in a can-do attitude that create the unique learning environment of the community peer-based programme. It is this interplay that can make this type of intervention a useful tool in the continuum of SCI care, irrespective of the level of comprehensiveness of the system of care. This type of community-based intervention is distinctly different from others and needs to be recognised as such. Because of the high level of perceived effectiveness, these programmes deserve to be better integrated in health-care systems and adequately funded. As most of the community peer-based programmes have not been adequately researched, service providers should be encouraged and supported to explore the effectiveness and cost-efficacy of these interventions.

\section{DATA ARCHIVING}

There were no data to deposit.

\section{CONFLICT OF INTEREST}

The authors declare no conflict of interest.

\section{ACKNOWLEDGEMENTS}

We would like to acknowledge Dr Michele Wolfe, Kenneth Chance-Larsen and Dr Luke Heales for providing editing support at the final stages of the manuscript. We would also like to acknowledge Dr Wendy Madsen for providing advice in the initial steps of this review.

1 World Health Organization. International Perspectives on Spinal Cord Injury. WHO: Geneva, Switzerland, 2013.

2 Smith M. Efficacy of specialist versus non-specialist management of spinal cord injury within the UK. Spinal Cord 2002; 40: 11-16.

3 Tator CH, Duncan EG, Edmonds VE, Lapczak LI, Andrews DF. Neurological recovery, mortality and length of stay after acute spinal cord injury associated with changes in management. Paraplegia 1995; 33: 254.

4 Parent S, Barchi S, Lebreton M, Casha S, Fehlings MG. The impact of specialized centers of care for spinal cord injury on length of stay, complications, and mortality: a systematic review of the literature. J Neurotrauma 2011; 28: 1363.

5 Divanoglou A, Westgren N, Bjelak S, Levi R. Medical conditions and outcomes at 1 year after acute traumatic spinal cord injury in a Greek and a Swedish region: a prospective, population-based study. Spinal Cord 2010; 48: 470-476.

6 Divanoglou A, Westgren N, Seiger $\AA$, Hulting C, Levi R. Late mortality during the first year after acute traumatic spinal cord Injury: a prospective, population-based study. J Spinal Cord Med 2010; 33: 117.

7 Devivo MJ. Sir Ludwig Guttmann Lecture: trends in spinal cord injury rehabilitation outcomes from model systems in the United States: 1973-2006. Spinal Cord 2007; 45: 713. 
8 Bloemen-Vrencken JHA, Witte LPD, Post MWM. Follow-up care for persons with spinal cord injury living in the community: a systematic review of interventions and their evaluation. Spinal Cord 2005; 43: 462.

9 Suddick K, O'Neill A. Reintegration and rehabilitation after spinal cord injury: a smallscale pilot study. Int J Ther Rehab 2009; 16: 535-544.

10 Cott C. Client-centred rehabilitation: client perspectives. Disabil Rehabil 2004; 26 : 1411-1422.

11 Dickson A, Ward R, O'Brien G, Allan D, O'Carroll R. Difficulties adjusting to postdischarge life following a spinal cord injury: an interpretative phenomenological analysis. Psychol Health Med 2011; 16: 463-474.

12 Nunnerley JL, Hay-Smith EJC, Dean SG. Leaving a spinal unit and returning to the wider community: an interpretative phenomenological analysis. Disability and Rehabilitation. Disabil Rehabil 2013, 35: 1164-1173.

13 Craig A, Nicholson Perry K, Guest R, Tran Y, Dezarnaulds A, Hales A et al. Prospective study of the occurrence of psychological disorders and comorbidities after spinal cord injury. Arch Phys Med Rehabil 2015; 96: 1426-1434.

14 Kennedy P, Sherlock O, Mcclelland M, Short D, Royle J, Wilson C. A multi-centre study of the community needs of people with spinal cord injuries: the first 18 months. Spinal Cord 2009; 48: 15.

15 Dattilo J, Caldwell L, Lee Y, Kleiber DA. Returning to the community with a spinal cord injury: Implications for therapeutic recreation specialists. Ther Recreation J 1998; 32: 13-27.

16 Craig A, Nicholson Perry K, Guest R, Tran Y, Middleton J. Adjustment following chronic spinal cord injury: determining factors that contribute to social participation. Br J Health Psychol 2015; 20: 807-823.

17 Sweet SN, Noreau L, Leblond J, Martin Ginis KA. Peer support need fulfillment among adults with spinal cord injury: relationships with participation, life satisfaction and individual characteristics. Disabil Rehabil 2016; 38: 558.

18 Letts L, Ginis KAM, Colquhoun H, Levac D, Faulkner G, Gorczynski P. Preferred methods and messengers for delivering physical activity information to people with spinal cord injury: a focus group study. Rehabil Psychol 2011; 56: 128-137 10p.

19 McAweeney MJ, Forchheimer M, Tate DG. Identifying the unmet independent living needs of persons with spinal cord injury. J Rehabil 1996; 62: 29-34 6p.

20 Heisler M. Building peer support programs to manage chronic disease: seven models for success. California HealthCare Foundation, 2006.

21 Erwin EJ, Brotherson MJ, Summers JA. Understanding qualitative metasynthesis: issues and opportunities in early childhood intervention research. J Early Interv 2011; 33: 186-200.

22 Harris J. Using qualitative research to develop robust effectiveness questions and protocols for Cochrane systematic reviews. 2011. In: Supplementary Guidance for Inclusion of Qualitative Research in Cochrane Systematic Reviews of Interventions [Internet]. Cochrane Collaboration Qualitative Methods Group. Available from: http://cqrmg.cochrane.org/supplemental-handbook-guidance.

23 Tong A, Flemming K, McInnes E, Oliver S, Craig J. Enhancing transparency in reporting the synthesis of qualitative research: ENTREQ. BMC Med Res Methodol 2012; 12: 181.

24 Thomas J, Harden A. Methods for the thematic synthesis of qualitative research in systematic reviews. BMC Med Res Methodol 2008; 8: 45.

25 Barnett-Page E, Thomas J. Methods for the synthesis of qualitative research: a critical review. BMC Med Res Methodol 2009; 9: 59.

26 Sandelowski M, Barroso J. Handbook for Synthesizing Qualitative Research. New York, USA: Springer Publishing Company, 2007.

27 Creswell JW, Miller DL. Determining validity in qualitative inquiry. Theory into Practice 2000; 39: 124-130.

28 Bates MJ. The design of browsing and berrypicking techniques for the online search interface. Online Rev 1989; 13: 407-424.

29 Rees R, Oliver K, Woodman J, Thomas J. Children's Views About Obesity, Body Size, Shape and Weight: a Systematic Review. London: EPPI-Centre, Social Science Research Unit, Institute of Education, University of London: University of London, London, UK: EPPI-Centre SSRU, Institute of Education, 2009.
30 Donabedian A. An Introduction to Quality Assurance in Health Care. New York, USA: Oxford University Press, 2003.

31 Walsh D, Downe S. Meta-synthesis method for qualitative research: a literature review. J Adv Nurs 2005; 50: 204-211.

32 Ashton-Shaeffer C, Gibson HJ, Autry CE, Hanson CS. Meaning of sport to adults with physical pisabilities: a disability sport camp experiecnce. Sociol Sport J 2001; 18 : 95-114.

33 Block P, Vanner EA, Keys CB, Rimmer JH, Skeels SE. Project shake-lt-up: using health promotion, capacity building and a disability studies framework to increase self efficacy. Disabil Rehabil 2010; 32: 741-754.

34 Conway T. Exploration of the Experiences and Perceptions of Spinal Cord Injured People who attend Outdoor Recreation Programmes. http://hdl.handle.net/10523/626. University of Otago: Dunedin, New Zealand, 2010.

35 Standal OF, Jespersen E. Peers as resources for learning: a situated learning approach to adapted physical activity in rehabilitation. Adapt Phys Act Q 2008; 25: 208-227.

36 Hammell KW. Experience of rehabilitation following spinal cord injury: a meta-synthesis of qualitative findings. Spinal Cord 2007; 45: 260-274.

37 Caldwell LL, Dattilo J, Kleiber DA, Lee Y. Perceptions of therapeutic recreation among people with spinal cord injury. Annu Ther Recreation 1994; 5: 13-26 14p.

38 Goodwin D, Peco J, Ginther N. Hiking excursions for persons with disabilities: experiences of interdependence. Ther Recreation J 2009; 43: 43-55.

39 Litchke LG, Hodges JS, Schmidt EA, Lloyd LK, Payne E, Russian CJ. Personal meaning of wheelchair rugby participation by five male athletes. Ther Recreation J 2012; 46: 26-41.

40 Jalovcic D, Pentland W. Telephone peer support program for women with spinal cord injuries. Proceedings of the 9th Congress of European Federation for Research in Rehabilitation, Budapest, Hungary, 26-29 August 2007. Int J Rehabil Res 2007; 30: 73-74 2p.

41 Perlman D. Project Quila: a case study in community-based rehabilitation. ProQuest Dissertations Publishing, 1997, p392.

42 Craig A, Rodrigues D, Tran Y, Guest R, Bartrop R, Middleton J. Developing an algorithm capable of discriminating depressed mood in people with spinal cord injury. Spinal Cord 2014; 52: 413.

43 Guest R, Craig A, Tran Y, Middleton J. Factors predicting resilience in people with spinal cord injury during transition from inpatient rehabilitation to the community. Spinal Cord 2015; 53: 682-686.

44 Bandura A. Self-efficacy: toward a unifying theory of behavioral change. Psychol Rev 1977; 84: 191-215.

45 Ryan RM, Deci EL. Self-determination theory and the for intrinsic motivation, social development, and well-being. Am Psychol 2000; 55: 68-78.

46 Ryan RM, Deci EL. Intrinsic and extrinsic motivations: classic definitions and new directions. Contem Edu Psychol 2000; 25: 54-67.

47 Deci E, Ryan R. Intrinsic Motivation and Self-Determination in Human Behavior. New York: Springer USA, 1985.

48 Bandura A. Social cognitive theory: an agentic perspective. Asian J Soc Psychol 1999; 2: 21-41.

49 Ginis K, Nigg C, Smith A. Peer-delivered physical activity interventions: an overlooked opportunity for physical activity promotion. Trans/ Behav Med 2013; 3: 434-443.

50 Rimmer JH, Riley B, Wang E, Rauworth A, Jurkowski J. Physical activity participation among persons with disabilities: barriers and facilitators. Am J Prev Med 2004; 26 : 419-425.

51 Dryden DM, Saunders LD, Rowe BH, May LA, Yiannakoulias N, Svenson LW et al. Utilization of health services following spinal cord injury: a 6-year follow-up study. Spinal Cord 2004; 42: 513.

52 Institute of Medicine (IOM). Evidence-based Medicine and the Changing Nature of Health Care: 2007 IOM Annual Meeting Summary. The National Academies Press: Washington, DC, USA, 2008.

53 Ginis KAM, Latimer-Cheung A, Corkum S, Ginis S, Anathasopoulos P, Arbour-Nicitopoulos $\mathrm{K}$ et al. A case study of a community-university multidisciplinary partnership approach to increasing physical activity participation among people with spinal cord injury. Trans/ Behav Med 2012; 2: 516-522.

Supplementary Information accompanies this paper on the Spinal Cord website (http://www.nature.com/sc) 